\title{
NUEVOS DATOS SOBRE LA CAPILLA DE LOS ALDERETE EN SAN ANTOLÍN DE TORDESILLAS Y EL ESCULTOR BARTOLOMÉ HERNÁNDEZ
}

\author{
POR \\ MANUEL ARIAS MARTÍNEZ
}

\begin{abstract}
The sculptor's presence Bartolomé Hernández in the conclusion of the altarpiece of the chapel of la Piedad (Tordesillas), gives information on their family relationship with Gaspar Becerra. At the same time the documental news on the interventions that were carried out in the altar piece, allow to atribute the florentine painter Benedito Rabuyate the painting of the same one. The architect's participation Pedro de Mazuecos in the works of the chapel, of the family Hoyos in the polichromy or of the painting mural, is some of the contributions that now are given to know.
\end{abstract}

La capilla de la Piedad, unida a la iglesia de San Antolín de Tordesillas, constituye uno de los ámbitos funerarios más significativos de la Castilla del siglo Xvi. El patronazgo ejercido sobre ella por la familia Alderete, que la eligió como panteón desde los inicios del siglo, determinó su embellecimiento. Lo destacado de la construcción y la importancia de los diferentes artistas que dejaron su huella en este conjunto, ha hecho que desde fecha muy temprana se reparara tanto en su arquitectura como en su amueblamiento. Diferentes publicaciones, que no queremos ahora reiterar ', han reflexionado sobre su contenido artístico. Ciertas novedades documentales, respecto al proceso constructivo y a la intervención final en el retablo son las únicas aportaciones que hoy podemos hacer a la historia de este hermoso espacio.

Aunque la capilla se fundará en los primeros años del siglo xvi, no será hasta el final de la centuria cuando esté concluido el conjunto tal y como ahora podemos contemplarlo. El enterramiento en nicho de Don Rodrigo Alderete, juez mayor de Vizcaya, es el resto más antiguo, fechado en 1527 y de plena raigambre goticista ${ }^{2}$. Del mismo instante deben ser las espectacu-

\footnotetext{
1 El compendio más completo sobre la capilla de la Piedad, donde además se recopila la bibliografía existente sobre el tema, se encuentra en Ara Gil, C.J. y Parrado del Olmo, J.Mª., Antiguo partido judicial de Tordesillas, Catálogo Monumental de la provincia de Valladolid, T. XI, Valladolid, 1980 (Reeditado en 1994), pp. 148-150 y 159-165. Sobre la arquitectura es necesario ver el trabajo de Heras García, F., Arquitectura religiosa del siglo XVI en la primitiva diócesis de Valladolid, Valladolid, 1975, pp. 256-262, quien dedica un capítulo a la arquitectura de la iglesia de San Antolín y a la capilla. En cuanto a temas más puntuales se irán citando en el transcurso de este trabajo otras publicaciones. Hemos consultado el Archivo Histórico Provincial de Valladolid (AHPV) y el Archivo Diocesano de Astorga (ADA).

${ }^{2}$ Ara Gil, CJ., Escultura gótica en Valladolid y su provincia, Valladolid, 1977, pp. 321-322.
} 
lares rejas, que acotan el ámbito y lo separan de la nave del templo, consideradas como uno de los más interesantes trabajos de forja del área vallisoletana ${ }^{3}$.

A mediados de siglo es cuando se produce una intervención general en la capilla, sufragada por el patrón de la misma Gaspar Alderete, que se prolongará hasta su muerte. Será entonces cuando se acomete el cuidado sepulcro de quien había sido el fundador del panteón, don Pedro Rodríguez Alderete, comendador de Santiago y regidor de Tordesillas, fallecido en 1501, que se dispone entonces en el centro de la capilla. Siguiendo esquemas berruguetescos el sepulcro, de gran calidad en el trabajo del alabastro, fue realizado por el taller del entallador Gaspar de Tordesillas. La obra de este maestro, centrada en la escultura en madera, llevó a Azcárate a pensar que su trabajo sería el de un contratista, donde se dejará notar una fuerte intervención de su taller ${ }^{4}$, aún sin precisar.

El retablo, obra a su vez del mismo Tordesillas, no estuvo destinado en su origen a este emplazamiento. Gaspar Alderete lo compra en 1550 a la comunidad de Santa Clara la Real de la villa, con destino a su capilla de la Piedad. La obra no admite dudas en cuanto a la intervención de Gaspar de Todesillas, probada documentalmente y dentro del estilo tradicional del maestro, en la labor de talla y ensamblaje. No estaba sin embargo terminado por completo el trabajo. Faltaba, además de la policromía, la obra de escultura, relieve y pintura que le diera forma. Con este motivo Alderete contrata en primer lugar los servicios de Juan de Juni, el escultor avecindado en Valladolid, para que se encargue de darle fin. La documentación localizada al respecto por García Chico, sirvió de base al estudio monográfico de la obra de Juni realizado por Juan José Martín González, a cuyo juicio fue decisiva la intervención del taller del maestro en la terminación del trabajo escultórico ${ }^{5}$.

\section{La reforma de la arquitectura}

La simple vista exterior de la capilla de la Piedad delata la secuencia de una serie de intervenciones que permiten fechar su ejecución al menos en dos fases diferentes. Visto el inicio del patronazgo de la familia Alderete en los primeros años del siglo XVI, fue la gran reforma iniciada en la mitad del siglo, la que configuró la visión espacial del conjunto hasta nuestros días. La cantería del exterior de la fábrica muestra una diferenciación desde la base de las ventanas hacia la parte superior, que corresponde, según veremos, con un recrecimiento de los muros con el fin de conseguir mayor altura. En este proceso se pudo reutilizar la crestería, cronológicamente perteneciente a la fase inicial, instalándose de nuevo en el remate de la construcción.

García Chico documentó la intevención de los canteros Diego de Hano y Juan Cantoral en 1556, comprometidos a realizar los arcos de la capilla mayor de la iglesia de San Antolín. El templo se estaba reformando al tiempo que la capilla, en una obra que todavía no se había

\footnotetext{
${ }^{3}$ Gallego de Miguel, A., Rejería castellana. Valladolid. Valladolid, 1981, pp. 42-47.

${ }^{4}$ La noticia documental, con los pagos a Tordesillas entre 1550 y 1562 , fue dada a conocer por Llaguno y Amirola, E., Noticias de los arquitectos y arquitectura en España, desde su restauración, Madrid, 1829, t. II, p. 22 y 176-8. José María de Azcárate hace esta precisión en Escultura del siglo XVI, Ars Hispaniae, t. XIII, Madrid, 1958, p. 181. Otros datos sobre el sepulcro aparecen, junto a la configuración general de la capilla, en Martí y Monsó, J., Estudios histórico-artísticos relativos principalmente a Valladolid, Valladolid, 1900, pp. 429-439.

${ }_{5}^{5}$ García Chico, E., Documentos para el estudio del arte en Castilla, Escultores, t. II, Valladolid, 1941, pp. 35-43. Martín González, J.J., Juan de Juni. Vida y obra, Madrid, 1974. En esta ocasión creemos simplemente curioso aportar un documento referido a las obras del retablo, por el que se adelanta en un año la constancia documental de la participación de Juni en el retablo. Se trata de una carta de pago de 1566 por las esculturas del retablo de la capilla de la Piedad (AHPV, Fernando del Torneo, 4432, fol. 127).
} 

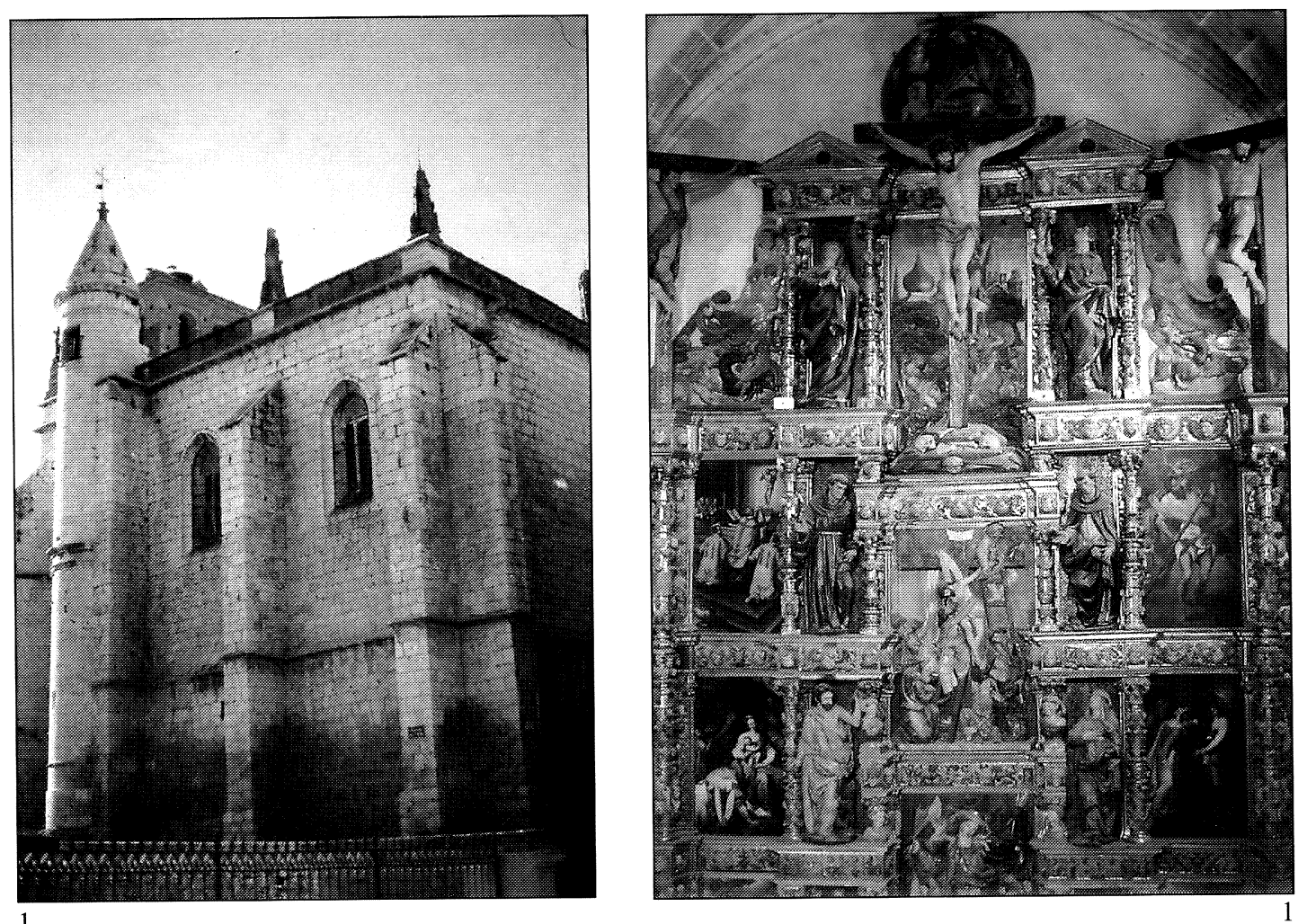

1

3

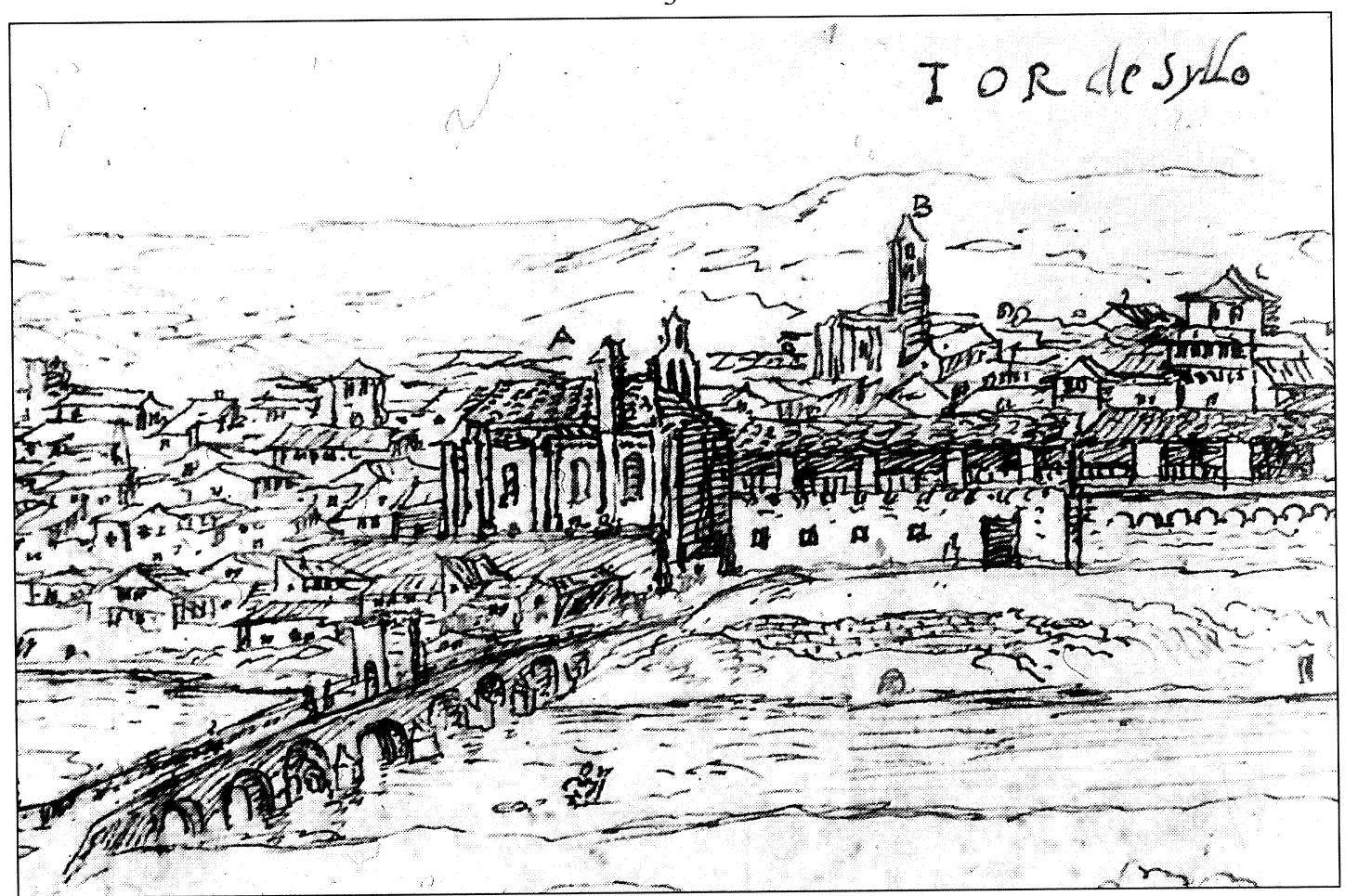

Fig. 1. Exterior de la capilla de la Piedad, en San Antolín de Tordesillas.

Fig. 2. Retablo de la Capilla de la Piedad.

Fig. 3. Detalle de la vista de Tordesillas de Anton van Wyngaerde, en el que se observa la capilla de la Piedad. 
pagado en $1560^{6}$, según publicó Parrado. Aunque no conocemos el instante en que se terminan las obras de la fábrica, sí sabemos ahora que en 1578 los beneficiados de San Antolín contratan con el entallador Juan de Malinas el trabajo de mudar de sitio el retablo mayor de la iglesia y recrecerlo en altura, después de las obras que se habrían terminado ${ }^{7}$, por lo que existe una cronología relativa para datar esa conclusión.

Al tiempo que en la iglesia, también García Chico señaló en 1559 el compromiso del cantero Juan de Zorrilla para elevar en la capilla de la Piedad la torrecilla cilíndrica o cubo, que albergaba en su interior la escalera de acceso a la tribuna y al mirador dispuesto en la zona superior ${ }^{8}$. Las obras de reforma de la capilla no debieron llevar un ritmo demasiado apresurado. El 30 de enero de 1579 documentamos el contrato llevado a cabo entre el patrono, Gaspar Alderete, y el carpintero de Tordesillas Juan Rojo, para hacer de nuevo el tejado de la capilla ${ }^{9}$. La noticia, con las peculiaridades aportadas en las condiciones en las que ha de transcurrir el trabajo, que finalizará a finales del mes de julio del mismo año, sirve indirectamente para conocer más datos sobre el proceso constructivo. Se señala expresamente que el carpintero debe hacer el tejado nuevamente, sustituyendo y aprovechando el maderamiento del existente, para permitir la entrada hacia las bóvedas, que se concluirían en esas fechas.

Las condiciones para la hechura hablan de que la obra se hará conforme a las trazas que realizó al efecto Pedro de Mazuecos, maestro de obras de Valladolid, sin que haya sido posible conocer más detalles referidos a este encargo y su datación concreta. El conocimiento del nombre del arquitecto encargado de la reforma es fundamental para valorar el cambio que se produce en la estructura del edificio, desde el concepto del nicho funerario de don Rodrigo Alderete a la vista final de la capilla. Él tuvo que ser quien dirigiera la obra de la sacristía, cubierta con bóveda de cañón, y la tribuna de los pies que se coloca sobre ella. Mazuecos «el viejo», es el tracista de las nuevas bóvedas de la capilla, sustituyendo a unas anteriores y elevando la altura general de todo el ámbito. Su relación con la villa está plenamente justificada a través de las reparaciones que lleva a cabo en el palacio de la reina Juana durante el reinado de Felipe II, que documenta García Chico ${ }^{10}$. Considerando la fecha en la que se inician las obras generales en la capilla, a partir de 1560, es muy lógico que el arquitecto trabajara en un lugar tan próximo al palacio real.

Puede ser también ilustrativo reparar en un documento de excepción, la vista de Tordesillas dibujada por Anton van den Wyngaerde entre los años 1565-1570 ${ }^{11}$. El fiel reflejo de la realidad, constante en la colección de vistas del artista, permite valorar con certeza la situación de la capilla de la Piedad en relación con la iglesia de San Antolín. La vista, hecha en el transcurso de las reformas que mencionamos, muestra con claridad una construcción más baja que la propia iglesia a la que se adosaba, con tres vanos y una torrecilla bastante más alta que la que podemos hoy observar. El testimonio, tan próximo en el tiempo a la modificación de la capilla aumenta de esta forma su interés.

\section{Colocación del retablo, pintura y estofado. La presencia de Bartolomé Hernández}

Terminada la obra de escultura, acometida por Juni y su taller, sobre la estructura de Gaspar de Tordesillas, van a permanecer detenidos los trabajos en el retablo durante algunos años.

\footnotetext{
${ }^{6}$ García Chicơ, E., Documentos para el estudio del arte en Castilla, Arquitectos, 1, Valladolid, 1940, p. 10. Heras García reconstruye la historia a partir de estos documentos en su trabajo citado. Posteriormente se han incorporado más noticias referentes a las obras que se llevaban a cabo en la iglesia, al menos hasta 1560, en la obra de Parrado del Olmo, J. Mª., Datos histórico-artísticos inéditos de la provincia de Valladolid, Valladolid, 1991, pp. 78-80.

7 AHPV, Francisco de Palencia, 4462, f. 64.

${ }^{8}$ García Chico, E., Documentos...Arquitectos, T. 1, p. 11.

${ }_{9}$ AHPV, Francisco de Palencia, 4463, f. 712 y ss.

${ }^{10}$ García Chico, E., Documentos...Arquitectos, p. 32. El arquitecto reclama pagos en 1582.
} 
Es de suponer que las propias reformas arquitectónicas de la capilli f̣renarían la terminación de la obra. Después de que en 1579 se realizara el nuevo tejado y se dicra por concluida la obra de fábrica, se firma el contrato entre Gaspar Alderete y el escultor vecino de Astorga, Bartolomé Hernández, para reparar el retablo, abandonado durante muchos años y con seguridad desmontado, policromarlo e instalarlo en el lugar destinado al efecto. Los términos del contrato, transcrito en parte por Martí y Monsó a partir del pleito que posteriormente tendría lugar ${ }^{12}$, son muy claros en la indicación de las instrucciones oportunas para dar la obra acabada ${ }^{13}$.

El encargo de la obra a Bartolomé Hernández viene desencadenado por el nombramiento de Ventura del Torneo como mayordomo de la capilla de la Piedad en $1578{ }^{14}$. El nuevo mayordomo es hermano de la esposa de Hernández, Luisa del Torneo. Como era habitual, las relaciones familiares están hablando al tiempo de vínculos profesionales. Hernández, que ha trabajado con Gaspar Becerra en Astorga, se traslada con él a Madrid y establece una perdurable relación con la familia Torneo, a la que pertenecía la mujer de Becerra, Paula Velázquez ${ }^{15}$. Aunque el gran pintor de Felipe II muere en 1568 y su esposa un año más tarde, Bartolomé Hernández seguirá manteniendo esos contactos a pesar de instalar su taller en Astorga, donde atendió la demanda producida por las innovaciones estéticas del esquema de Becerra en el retablo catedralicio. De este modo Hernández está en Tordesillas en $1574{ }^{16}$, donde se casará con Luisa del Torneo, sobrina de la mujer de Becerra y hermana de Baltasar del Torneo, otro de los escultores del taller que trabaja en los sitios reales.

A partir de este momento son muchas las referencias a Bartolomé Hernández en la documentación notarial de Tordesillas. El retablo de la capilla de los Alderete es el motivo principal, desde su contrato a su tasación y los distintos pagos que se le efectúan, como tendremos ocasión de comprobar. Asuntos familiares de otra índole le hacen aparecer coincidiendo con su estancia en la villa, firmando como testigo un codicilo del bachiller Pedro del Torneo en 1581 o figurando como fiador en la curaduría de su sobrino político, Baltasar Ugarte del Torneo, hijo del citado escultor homónimo, en $1583{ }^{17}$.

Centrémonos ahora en su debatida intervención en el retablo. No es aquí el lugar de reiterar datos conocidos y publicados en repetidas ocasiones sobre su actuación, como se señala en las condiciones del contrato, en las puntualizaciones desprendidas del pleito dado a conocer por Martí y Monsó, o en la documentación aportada por García Chico. Intentaremos únicamente resumir la situación para señalar algunas novedades. Como consecuencia del contrato con Hernández el pintor florentino asentado en Valladolid, Benedito Rabuyate, plantea una quere1la. Alderete se había comprometido a encargarle la pintura de las tablas que formaban el retablo, así como la policromía del mismo, incluso con un compromiso notarial ${ }^{18}$. Al ser fiador de Juni en la obra de escultura, se desplazó a Tordesillas y trabajó haciendo retratos para los Alderete, pensando en cobrar su importe cuando tuviera que acometer la obra del retablo. El en-

\footnotetext{
$"$ Kagan, R.L., ( dir.), Ciudades del siglo de Oro. Las vistas españolas de Anton van den Wyngaerde, Madrid, 1986, pp. $379-381$.

${ }^{12}$ Las primeras noticias sobre la intervención de Hernández en el retablo las proporcionó Martí y Monsó a través del pleito que este mantiene con Rabuyate en la Chancillería de Valladolid. La transcripción de una parte considerable de las declaraciones de los testigos, que utilizamos frecuentemente en este trabajo, ha servido para conocer la actividad de ambos artistas y su círculo (Martí y Monsó, J., Op. cit., 432-439).

13 AHPV, Francisco de Palencia, 4464, f. 1082-1085.

14 El nombramiento se registra el 24 de julio. AHPV, Francisco de Palencia, 4462, f. 694 y ss..

15 Las relaciones familiares de Becerra se plasmaron en un árbol genealógico que se puede consultar en Arias Martínez, M., «Gaspar Becerra, escultor o tracista. La documentación testamentaria de su viuda Paula Velázquez», Archivo Español de Arte (AEA), n 283, Madrid, 1998, pp. 273-288.

${ }^{16}$ El 14 y el 27 de febrero se registran en los protocolos de Tordesillas las cartas de arras y dote de Bartolomé Hernández, ensamblador y vecino de la ciudad de Astorga, y Luisa del Torneo. AHPV, Francisco del Torneo, 4524, f. 50, 70, 72.

17 AHPV, Francisco del Torneo, 4531, f. 45; 4533, f. 526 y ss.

18 AHPV, Francisco del Torneo, 4519, f. 373. El compromiso está fechado el 14 de mayo de 1569.
} 
cargo a Hernández desató el pleito, que tuvo su final en una ejecutoria dictada por la Real Chancillería el 8 de mayo de $1582{ }^{19}$, por la que Rabuyate percibiría una alta indemnización, mientras que Hernández proseguiría con la obra iniciada.

Antes del inicio del litigio, con el escrito presentado por Rabuyate ante el corregidor de Tordesillas el 10 de marzo de 1581, Hernández ya estaba instalado en Tordesillas trabajando en su encargo. Debemos pensar que el mal estado del retablo, según se deduce de la documentación, hacía necesaria la intervención de un hábil ensamblador que reparara los daños, añadiera las partes perdidas y colocara el conjunto en su sitio. Además, en lo referente tanto a la policromía como a la pintura de pincel actuará como un contratista, buscando a los oficiales necesarios, conocedores de tales materias.

El día 7 del mismo mes había firmado un contrato con el batidor de oro de Medina del Campo, Lope de Galbez ${ }^{20}$, con el fin de proveerse del oro necesario para el dorado. Galbez se obliga a entregar todos los panes de oro batidos necesarios para dorar el retablo a 84 reales cada mil panes. Cada mes entregará 4000 unidades hasta que se acabe la obra. Sobre la conclusión objetiva de este dato es necesario reconsiderar esta nueva intervención. Lope de Galbez es, en primer lugar, un batidor que ha estado relacionado con el abastecimiento del oro para la policromía del retablo de la catedral de Astorga. Su testamento, publicado por García Chico ${ }^{21}$, menciona las cuentas que tenía con los herederos de Gaspar de Hoyos y con Gaspar de Palencia, los dos maestros encargados de esta tarea. Es por tanto lógico que Bartolomé Hernández recurra a él, dado su trabajo directo en el retablo de Astorga, que tan bien conocía.

El documento cuenta con la presencia de dos artistas que actúan como testigos, Francisco y Rafael de Hoyos, vecinos de Cuenca de Campos, que juran conocer al batidor. Ambos figuran citados más tarde, testificando en favor de Hernández, a lo largo del pleito con Rabuyate. Su presencia en el documento de contrato del oro es fundamental y, de un modo indirecto sirve para atribuirles sin género de dudas la autoría de las policromías del retablo de la Piedad. El taller de la familia Hoyos, que trabajó en Astorga a las órdenes de Gaspar, uno de los pintores de Becerra, mantiene el oficio después de su muerte. Los motivos ornamentales utilizados son los mismos que los empleados por Hoyos en la mitad del retablo de Astorga que se encarga de policromar, lo que además se confirma con la certeza documental de la herencia recibida por Francisco a la muerte de su hermano y de los modelos que éste tenía en su poder ${ }^{22}$.

Las relaciones artísticas que se establecieron en torno al retablo catedralicio de Astorga van más allá de las similitudes entre maestros de un mismo taller. La magnitud de la propia obra y lo que supone de formación de oficiales y de difusión de modelos, fue creando una red que colaboró a la perduración de un esquema consolidado. Hernández recurrirá para la tasacion de la obra de los Alderete, posiblemente siguiendo la indicación de los Hoyos, a Juan de Durana, el pintor zamorano que también tasó el retablo de Astorga en 1573 junto a Diego de Urbina ${ }^{23}$.

\footnotetext{
19 ARCHV, Reales Ejecutorias, c. 1464

${ }^{20}$ AHPV, Francisco del Torneo, 4531, f. 606 y ss.

${ }^{21}$ García Chico, E., Documentos para el estudio del arte en Castilla. Pintores, t. III, 1, Valladolid, 1946, pp. $199-201$. En el testamento, redactado en 1575 , se mencionan otros artistas vinculados con el foco astorgano de Becerra, como Gaspar de Bilbao o Esteban Jordán. García Chico también menciona en su obra otros contratos de Gálbez.

${ }^{22}$ González García, M.A., y Arias Martínez, M., «A propósito de Gaspar de Palencia», Boletín del Museo de Bellas Artes de Bilbao 1993. Bilbao, 1994, pp. 21-47

${ }^{23}$ Los documentos sobre la tasación fueron dados a conocer por García Chico, E., Documentos para la historia del arte en Castilla. Escultores, T. II, Valladolid, 1941, pp. 41-43. Durana es nombrado tasador por la parte de Hernández.
} 

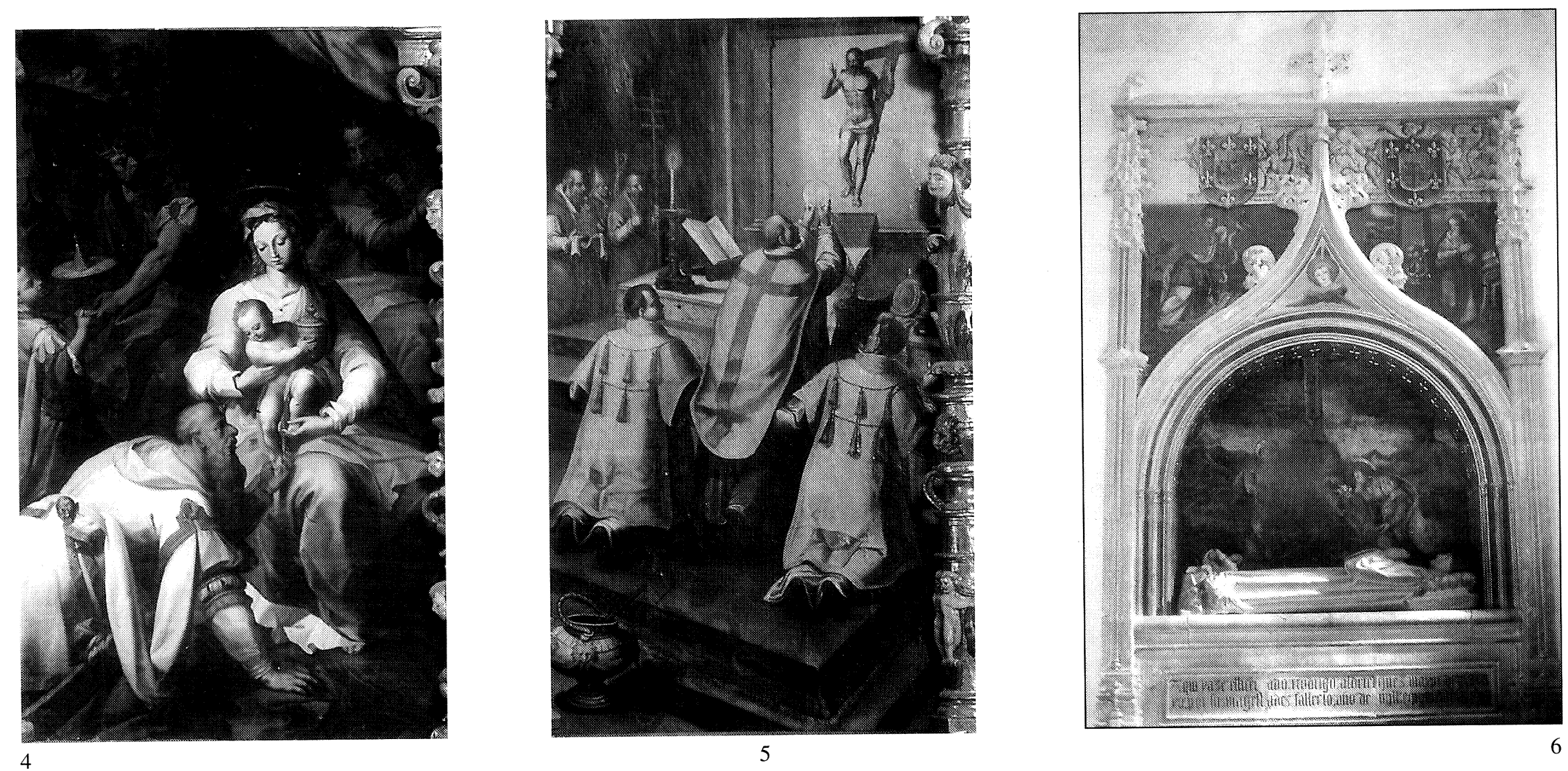

Fig. 4. Adoración de los Magos. Rretablo de la Capilla de la Piedad.

Fig. 5. Misa de San Gregorio. Retablo de la Capilla de la Piedad.
Fig. 6. Sepulcro de Rodrigo Alderete, con las pinturas murales del Llanto sobre Cristo muerto y la Anunciación. 


\section{La pintura de las tablas}

En otro sentido se plantea una cuestión problemática en la historia del retablo, la que se refiere a la ejecución de la pintura de las tablas. No existe un hilo conductor en el programa de la pintura sobre tabla que completa el retablo. Son seis composiciones al óleo representando episodios sagrados sin una especial ligazón temática o de disposición. La Visitación, la Epifanía y el Bautismo de San Juan son tres manifestaciones de la vida de Cristo inconexas en la secuencia de los acontecimientos evangélicos. La Misa de San Gregorio, San Cristobal y la pareja formada por San Benito y Santa Escolástica, son las otras tres tablas con asuntos de santos, faltas también de relación directa alguna. Las razones de su representación no son más que la habitual muestra de las devociones particulares de la familia comitente, según comprobaremos.

En origen la resolución del pleito condenando a Alderete a satisfacer económicamente a Rabuyate, poniendo perpetuo silencio al pintor, ha venido interpretándose del modo más obvio. Bartolomé Hernández se vería obligado a afrontar la totalidad de la obra tal y como se obligaba por el contrato suscrito con el patrón de la capilla. El hecho de tratarse de un escultor hizo suponer que en este tipo de trabajos su función hubo de ser la de un supervisor y la obra de pincel sería traspasada a algún pintor de su confianza. A partir de ese instante, sin entrar en más consideraciones, se atribuyó la pintura ${ }^{24}$ a un desconocido maestro astorgano, seguidor de los esquemas de Becerra, pensando en los testigos presentados por Hernández en el pleito, que se decían ser pintores y procedían del entorno diocesano de Astorga.

La calidad pictórica de las tablas de Tordesillas permite hoy, con más conocimientos sobre la pintura astorgana del momento, dejar a un lado esta hipótesis. Ninguno de los pintores que trabajan en este ámbito y de los que hemos conservado ejemplos, pudo ser capaz de afrontar tal empresa. Las composiciones diseñadas por Becerra, traspasadas de la escultura a la pintura, forman el bagaje inicial, degenerado y falto de genialidad, de un grupo de artistas mediocres que abastecen un mercado preferentemente rural. A pesar de la existencia de algunos talleres que hacen gala de mayores habilidades técnicas, distanciándose de los demás, como sucede con los dirigidos por Pedro de Bilbao o Jerónimo de Salazar ${ }^{25}$, utilizando abundantemente las fuentes impresas y los grabados, la mayor parte de ellos no llegan a dar la talla en cuanto a innovaciones, con una pintura de gran simplicidad, tal es el caso de Hernando Pabón, en el retablo de la parroquial de Lagunas de Somoza (León), de Juan de Villena o de Gabriel Martínez.

Así las cosas, Post aportó un nuevo nombre a la hora de atribuir las pinturas de este debatido retablo, descartada la posibilidad de que fuera Rabuyate su autor ${ }^{26}$. Para él la identidad del maestro medinense Antón Perez, documentado en varias ocasiones por García Chico ${ }^{27}$, era la indicada para haber llevado a cabo semejante trabajo. La certeza en la documentación de una tabla encargada a este artista para Pozaldez, le llevó a establecer una secuencia de comparaciones con su estilo, al que no dudaba en adjudicar las tablas de Tordesillas. Examinada con más detenimiento la propuesta pensamos que no es adecuado el juicio. Las formas empleadas por Antón Pérez en Pozaldez, a través de las fotografías conservadas, no tienen nada que ver con las citadas tablas, sin embargo sí existe una interesante relación con dos pinturas de Valbue-

\footnotetext{
${ }^{24}$ Martí y Monsó, J, Op. cit., pp 432-439. Ara Gil, C.J. y Parrado del Olmo, J. Ma , Op cit., pp. 159 y ss.

${ }^{25}$ García Iglesias, J.M., La pintura manierista en Galicia, La Coruña, 1986, p. 73 y ss.. En el libro se habla del área de influencia de la diócesis de Astorga en Orense.

${ }^{26}$ Post, Ch. R., The later Renaissance in Castille, A history of Spanish painting, t. XIV, Cambridge, Harvard, 1966, pp. $122-127$.

27 García Chico, E., Documentos... Pintores, t. III, 1, pp. 126-146 y otras.
} 
na que Post hace salir de su taller ${ }^{28}$. Efectivamente Antón Pérez es un pintor de cierta calidad, influenciado por los modelos italianos que se difunden en la época, con el que sí se pueden relacionar otras pinturas del entorno vallisoletano como el Llanto sobre Cristo muerto, conservado en la parroquia de los Santos Juanes de Nava del Rey ${ }^{29}$

Pero no termina aquí la historiografía de las atribuciones. Recientemente el profesor Parrado del Olmo ofrecía una propuesta a este prolongado problema de autorías ${ }^{30}$. La opción de que la obra fuera subcontratada por Hernández a un pintor que estuviera trabajando en Astorga, sigue teniendo para él plena validez, pensando en uno de los pintores más notables de este instante, vinculado tanto con Astorga como con Valladolid, Gaspar de Palencia. No obstante encontramos una larga serie de diferencias con su forma de entender la pintura, después de comprobado el alcance de su producción ${ }^{31}$, especialmente en lo que toca al tratamiento lumínico y a la valoración del claroscuro, sin olvidar el uso de composiciones con intenciones escenográficas. La comparación con obras suyas documentadas, como el retablo zamorano de Tiorrodrigo o las pinturas de Santa Marta de Astorga, dificultan mantener esta atribución, complicada además por cuestiones personales, si conocemos la situación en la que queda la policromía del retablo de Astorga después de la muerte de Gaspar de Hoyos. La enemistad entre Palencia y la familia de Hoyos les lleva a un pleito por la finalización de las obras. Es difícil suponer que en la relación existente entre Hernández y los familiares de Hoyos, encargados sin duda de la policromía del retablo de la Piedad, tenga algo que ver Gaspar de Palencia.

En cuanto a la posibilidad de la participación de Jerónimo Vázquez, difícilmente a la vista de las obras documentadas o atribuidas a su mano, se puede considerar su intervención en la pintura de estas tablas ${ }^{32}$. La mediocridad de sus resultados pictóricos, a pesar de contar con los modelos de Becerra, según se refleja en la documentación del maestro, no le sirvió para acometer una obra caracterizada por la incorporación de las novedades del momento, continuando su actividad en una órbita muy provinciana.

Sin embargo hay muchos argumentos para atribuir a Rabuyate la ejecución de las pinturas, incluso a pesar de la falta de documentación contractual específica que permita aseverarlo ${ }^{33}$. Las conclusiones de la ejecutoria del pleito señalan la reivindicación del pintor, basada no sólo en el compromiso de Gaspar Alderete de encargarle la obra, sino en cierta deuda que mantenía con él. En su estancia en Tordesillas como fiador de Juni, realizó cuatro retratos valorados en 100 ducados, de los hijos de Alderete y sus conyuges además, indica, de otras pinturas de mucho valor, sin darnos noticia de los temas que trataban. De la valoración en 100 ducados a la compensación que la sentencia obliga finalmente a pagar a Alderete, elevada a 400, en razón de las pinturas y tablas entregadas por Rabuyate, hay una gran diferencia aparentemente inexplicable.

La cantidad es elevada, si observamos que el contrato con Bartolomé Hernández para reparar el ensamblaje y realizar la policromía del retablo se fijaba en 700 ducados. En las diligencias del proceso se señala que Alderete ofreció a Rabuyate hacer la obra de pincel del retablo y que éste rechazó la propuesta, sin que se entren en mayores detalles. En la terminación

\footnotetext{
${ }^{28}$ Ibidem, pp. 137-139, en cuanto a la documentación referida a Pozaldez. Arias Martínez, M., «El Monasterio de Valbuena de Duero (Valladolid).La decoración manierista de su claustro bajo», AEA, n² 277, 1997, pp. 17-36.

${ }^{29}$ García Chico, E., y Bustamante García, A., Catálogo monumental del partido judicial de Nava del Rey, Valladolid, 1972, p. 32.

${ }^{30}$ Catálogo de la exposición Tordesillas, 1994, Madrid, 1994, p. 138 (la ficha está realizada por J.Ma Parrado del Olmo).

${ }^{31}$ González García, M.A., Arias Martínez, M., «Op. cit.», Boletín del Museo de B. A. de Bilbao, pp. 21 y ss.

32 Ibidem, pp. 26-28. Parrado del Olmo, J.M ${ }^{\mathrm{a}}$., «El antiguo retablo mayor de Berceruelo (Valladolid). Consideraciones sobre su traza arquitectónica y la problemática de su pintura», en Estudios de Arte. Homenaje al profesor Martín González, Valladolid, 1995, pp. 533-542.
} 
del conjunto pudieron utilizarse tablas pintadas por Rabuyate destinadas al retablo, que estaban en poder de Alderete, descartada la posibilidad de su realización por cualquiera de los pintores astorganos que figuran como testigos en el pleito entre Hernández y Rabuyate, o por cualquiera de los que en esos instantes trabajaban en Valladolid y su entorno.

Es además curioso otro aspecto anecdótico, en relación con el programa de las pinturas, que puede llevarnos a pensar en la ejecución de las tablas coincidiendo con la estancia de Rabuyate en Tordesillas, ocupado en los retratos familiares de Alderete. Sus hijos se llaman Cristobal y Gregoria, y ambas advocaciones figuran entre las elegidas para conformar el programa iconográfico del retablo con la representación de San Cristobal y la Misa de San Gregorio. La escena de la Epifanía alude sin duda alguna al santo particular del propio patrón de la capilla, Gaspar Alderete ${ }^{34}$.

En definitiva, la propia calidad pictórica de las tablas se distancia de lo que es habitual en la pintura vallisoletana de esas fechas. Composiciones como las de la Epifanía acusan una marcada influencia de la pintura de Correggio y en general de los pintores italianos de los que Rabuyate posee copias abundantes. La relación formal con las dos tablas perdidas de Valbuena y con el Retablo de la Resurrección, conservado en el Museo Nacional de Escultura, permitiría poder hablar de un grupo de obras salidas de su taller. El tratamiento de fondos, paisajes y el peculiar concepto lumínico son diferentes y de una mayor calidad a los empleados por los pintores que en esos momentos están trabajando en el entorno, hasta la llegada de Gregorio Martínez, el que hubo de ser el más aventajado discípulo del pintor florentino.

\section{Terminación del retablo y últimos pagos}

La terminación de la obra del retablo, como solía ser frecuente, no suponía el pago inmediato del trabajo del artista. La tasación realizada en 1583, con la entrega finalizada de la obra encargada, fue el punto de arranque de una serie de pagos que se prolongan nada menos que hasta 1598. Bartolomé Hernández muere en 1588 y es su viuda Luisa del Torneo, casada ya en Astorga en segundas nupcias, quien sigue recibiendo el dinero desde Tordesillas a través de poderes notariales ${ }^{35}$. No supone ninguna novedad la aportación de esta documentación, pero si pueden ser de utilidad algunos de los términos que se ocupan del trabajo realizado por Hernández o de los sistemas de pago.

${ }^{33}$ Esta suposición ya había sido formulada por Angulo Iñiguez, D., Pintura del Renacimiento en Ars Hispaniae, t. XII, Madrid, 1954, p. 195 y por Caamaño Martínez, J.M ${ }^{\mathrm{a}}$., «Tendencias manieristas en la pintura vallisoletana de la segunda mitad del siglo XVI», BSAA, T., XXVIII, 1962, p. 19.

${ }^{34}$ La representación de las devociones particulares de la familia en el retablo no es por otro lado ninguna excepción en el panorama de la época. Pensamos que debe señalarse especialmente en casos como éste donde no hay un programa homogéneo en lo que se refiere al ciclo de pinturas, de manera que es a través de las devociones privadas como se le puede dar una explicación. Que las tablas responden a esa idea lo corroboran noticias indirectas como el inventario de 1590 de Gaspar Alderete, en el que se nombra a dos esclavos «color de membrillo» nacidos en la casa bautizados como Benito y Escolástica, dos advocaciones que también aparecen en el banco del retablo. AHPV, Francisco de Palencia, 4474 , f. 393 v.

${ }^{35}$ El 30 de agosto de 1588 Hernández firma como fiador del entallador astorgano Hernando de Espinosa, para la realización de la cajonería de la iglesia de Villagarcía (ADA, Andrés Becerra, 1588, s.f.). El 11 de diciembre su viuda está resolviendo los problemas de su herencia. Las diferentes reclamaciones y los pagos efectuados a Luisa del Torneo se registran en diferentes documentos del AHPV. En 1590 Luisa del Torneo otorga poder en Astorga a su pariente el bachiller Pedro del Torneo para cobrar lo que se le adeuda en Tordesillas (Juan de Medina, 4708, f. 35-39). De los años 93 al 98 recibe nuevos pagos hechos por su hermano Ventura del Torneo, rematándose finalmente la deuda según se especifica en las Cuentas de la Capilla de 1598 (Francisco de Palencia, 4478, f. 1104-1109; 4481, f. 179-183; 4483, f. 3 y ss). Estas noticias sirven para conocer detalles particulares de la viuda de Hernández, que se casa de nuevo en Astorga con Juan Alonso, aunque sigue vinculada con su lugar natal con la compra de un censo en Velilla (Valladolid) en 1593 (Francisco de Palencia, 4477, ff. 933-936). 
En la mayor parte de los documentos de pago Hernández aparece siempre avecindado en Astorga, como escultor, aunque alguna vez se le mencione como entallador. Sí se ha perdido el término ensamblador, la dedicación profesional que lo señalaba al comienzo de la obra, con la que además se le unía desde su relación con Becerra en los retablos de la catedral de Astorga y de las Descalzas de Madrid. En efecto Hernández se reconvierte hacia el trabajo de la escultura, con una notable calidad técnica desde su regreso a Astorga en 1569, sin que por ello dejara de acometer otras tareas relacionadas con su profesión inicial de ensamblador, visibles en los extraordinarios retablos que jalonan los pueblos del valle de Vidriales. Esa habilidad en el trabajo de la madera había sido aprovechada por Becerra no sólo en las laboriosas operaciones del ensamblaje, sino en la misma labor de talla que hubo de salir de sus manos, siguiendo las indicaciones precisas del director de equipo.

Los pagos por su obra en la capilla de la Piedad, poco específicos en cuanto al concepto, suelen sin embargo hacerse por dorar y estofar el retablo. De este modo junto a la obra principal de ensamblaje la policromía del conjunto sería dirigida por él como un mero contratista. Que en los conceptos no se mencionen los trabajos de pincel no quiere decir que no fuera Hernández quién se encargara de adjudicar su realización, al igual que no se menciona de forma específica el ensamblaje ni la reparación del retablo. En los documentos se reflejará lo que fue la intervención más costosa en el conjunto, el uso del oro y la policromía de mazonería y relieves. Con ocasión del pleito, Hernández señala los trabajos que lleva acometidos en el retablo, entre los que destaca la situación de las piezas en la fase de embolado, dentro del proceso polícromo. Si bien es cierto que señala haber llevado oficiales para hacerse cargo de la obra de pincel, en ningún caso se afirma que esos mismos oficiales hayan realizado los trabajos. Además, el nombramiento de Durana como tasador, experto en la revisión de grandes obras de policromía según apuntamos, puede ayudar a justificar que Hernández se encargara únicamente de controlar la policromía y no de la pintura de las tablas, como venimos afirmando.

\section{Otras intervenciones pictóricas en la capilla}

Tasado el conjunto parece que las obras importantes en la capilla hubieran terminado. Quedaban algunos cabos sueltos y quien detenta el patronato de la capilla sigue empeñado en dar buen fin a la disposición interna del espacio, que no estará del todo terminada hasta el año 1589 cuando una Visita efectuada al templo así lo declare ${ }^{36}$. Por este motivo el 21 de julio de 1584 firma un contrato con un pintor vallisoletano del que apenas tenemos noticias, pese a su pertenencia a una familia de artistas con trabajo abundante en el área de influencia de la ciudad. Será Gabriel Vázquez de Barreda ${ }^{37}$, quien se compromete a realizar unas obras pictóricas de reparación, que sirven para corroborar la reforma general de la capilla y la nueva realización de las bóvedas siguiendo las mencionadas trazas de Mazuecos.

El pintor no sólo repintará el nicho sepulcral de don Rodrigo Alderete, el resto más evidente de la originaria construcción, sino también decorará los ángeles tenantes de escudos heráldicos que se disponen en las esquinas inferiores de la bóveda, terminada recientemente. La descripción del contrato especifica una clarísima tarea de repinte en todo lo que toca al sepul-

\footnotetext{
${ }^{36}$ El dato de la Visita fue dado a conocer por Heras García, F., Op cit., p. 260.

${ }^{37}$ El artista es mencionado por Ceán Bermúdez, así como en la historiografía artística vallisoletana, desde Martí y Monsó a Agapito y Revilla. Más recientemente se puede ver en Parrado del Olmo, J. M ${ }^{a}$., «El antiguo retablo mayor de Berceruelo (Valladolid)..., 1995, pp. 533-542.
} 
cro del nicho, desde las escenas elegidas de la Anunciación y la Quinta Angustia, que han llegado con dificultades a nuestros días, hasta la misma policromía del yacente ${ }^{38}$. Los esquemas empleados seguirían muy de cerca las composiciones anteriores.

${ }_{38}$ AHPV, Francisco de Palencia, 4468, f. 300 y ss. En el contrato dice que hará la obra «en el arco primero de la dicha capilla que esta junto al altar mayor adonde esta un bulto de alabastro en la forma e manera siguiente, primeramente are de pincel la ystoria de la quinta angustia en la pared frontera de adentro del dicho arco con todas las figuras que solia tener, yten porne otros colores en todo lo tocante al dicho arco en las partes donde fuere menester y estubiere defetuoso y todo el color blanco lo lucire de nuebo de manera que todo ello quede bien, yten la salutaçion que esta ençima del dicho arco la hare de pinçel de nuebo de manera que quede vien acabada, yten los dos escudos que estan en la frontera los abibare de color de manera que queden bien lucidos y lo blanco questa en la tabla de ello lo mismo, yten el bulto y un muchacho y un perrillo questan a los pies del los encarnare los rrostros e manos y los querpos los lucire de blanco de manera que todo ello quede bien adornado, yten el chirubin questa en medio del arco le encarnare el rrostro y colorire las alas $y$ dorare lo que en el fuere menester, yten encarnare corare y lucire las quatro cantoneras y los angeles questan en ellas $y$ los escudos que tienen en las manos poniendo en cada parte de ello lo que fuere menester». 